\title{
Development of Fe-Mn-Si based shape memory alloys with no necessity of "training"
}

\author{
S. Kajiwara, D.Z. Liu*, T. Kikuchi and N. Shinya \\ National Research Institute for Metals, 1-2-1 Sengen, Tsukuba 305-0047, Japan
}

\begin{abstract}
In ar. ttempt to modify the current Fe-Mn-Si based shape memory alloys so that so-called the "training" treatment may be no more necessary, a small amount of $\mathrm{Nb}$ and $\mathrm{C}$ were added to Fe-Mn-Si based alloys to form $\mathrm{NbC}$ precipitates by aging. The existence of small coherent $\mathrm{NbC}$ precipitates in austenite greatly increases the shape recovery and the recovery force without the "training". For Fe-28Mn-6Si-5Cr-0.5NbC (mass \%), 100-80\% shape recovery are obtained for tensile strains of $1-4 \%$ and, for $\mathrm{Fe}-14 \mathrm{Mn}-6 \mathrm{Si}-9 \mathrm{Cr}-5 \mathrm{Ni}-0.5 \mathrm{NbC}, 100-80 \%$ shape recovery are attained for tensile strains of 1-3\%. The maximum recovery force is $155 \mathrm{MPa}$ for the former alloy and $130 \mathrm{MPa}$ for the latter. The increase in recovery force of the former alloy compared with the corresponding $\mathrm{NbC}$ free alloy is $45 \mathrm{MPa}$. Our preliminary experiments with transmission electron microscope and atomic force microscope indicate that the stress-induced martensite structures formed in the NbC containing alloys are nearly the same as those in the "trained" sample of the $\mathrm{NbC}$ free alloys in accordance with the prediction recently made by Kajiwara.
\end{abstract}

\section{INTRODUCTION}

Since the discovery of shape memory effect (abbreviated as SME) in Fe-Mn-Si alloys in 1982 by Sato et al.[1], no major practical applications of this shape memory alloy and its modifications have been made so far despite of their low cost, good workability, good machinability and good weldability. The reason for this is that the SME in these alloys is not so good as that of Ti-Ni based shape memory alloys. In order to obtain nearly perfect shape recovery in Fe-Mn-Si base alloys, a special thermomechanical treatment, so-called "training", must be performed. The "training" treatment consists of several thermal cycles of deformation by stress induced martensitic transformation and subsequent heating for the reversion to austenite. It is obvious that this treatment will raise the production cost of this shape memory material and, for somewhat complicated shapes, it would be impossible to make the "training" treatment. Therefore, in order to promote industry applications in various fields, it is absolutely necessary to modify those Fe-MnSi based alloys so that the "training" treatment may not be necessary.

Bearing in mind that the mechanism of the "training" effect on SME in this alloy must be first clarified for developing "training-free" new alloys, we have been studying microstructures in the "trained" sample with various magnifications ranging from $\mu \mathrm{m}$ to sub-nm [2-7] and found that the most important condition for exhibiting good SME is as follows. The stress-induced martensite plates produced by deformation at room temperature must be very thin $[2,4,5]$ (as thin as about $1 \mathrm{~nm}$ in width), and have the same variant and uniformly distributed in austenite [6,7]. It is presumed that, to realize such microstructures in the deformed specimen, stacking faults acting as martensite nuclei must be uniformly distributed in austenite before deformation [4,5,7]. In other words, we can say that the existence of uniformly distributed martensite nuclei in austenite is the prerequisite for exhibiting good SME in Fe-MnSi based alloys. As was recently suggested by Kajiwara [4], coherent fine precipitates in austenite could

- Present address: Shape Memory Materials Engineering and Research Center, College of Materials Science and Engineering, Tianjin University, Tianjin 300072, China. 
be potential nuclei because the martensite would be easily nucleated at these precipitates when external stress is applied. In the present work, in an attempt to modify Fe-Mn-Si based shape memory alloys so that the "training" treatment is no more necessary, we have introduced $\mathrm{NbC}$ precipitates in austenite to serve as martensite nuclei. It seems that the $\mathrm{NbC}$ precipitate $(\mathrm{NaCl}$ type structure) is ideal for such purpose because it has a large elastic strain field as was shown for an Fe-Mn binary alloys [8] and the binding force between $\mathrm{Nb}$ and $\mathrm{C}$ atoms in the $\mathrm{NbC}$ compound is so large that the addition of these elements do not give any effect on chemical free energies of the fcc and hcp phases, which keeps the transformation temperatures unchanged. It was actually found that the $\mathrm{NbC}$ addition to the conventional Fe-Mn-Si based alloys produces remarkable effect to improve SME. The present paper reports the essential part of these results.

\section{EXPERIMENTAL}

The composition of newly designed alloys is listed in Table 1 . Two typical alloys, $\mathrm{Fe}-28 \mathrm{Mn}-6 \mathrm{Si}-9 \mathrm{Cr}$ and $\mathrm{Fe}-14 \mathrm{Mn}-6 \mathrm{Si}-9 \mathrm{Cr}-5 \mathrm{Ni}$ (mass\%), were selected as reference alloys. The alloys were prepared by vacuum induction melting, with introduction of argon at the time of $\mathrm{Mn}$ melting. The ingots of $45 \times 64 \times 100 \mathrm{~mm}$ were forged and hot-rolled to $20 \mathrm{~mm}$ thickness, and then square-pillar shaped specimens with the size of $18 \times 20 \times 70 \mathrm{~mm}$ were cut out and solution treated at $1470 \mathrm{~K}$ for $10 \mathrm{~h}$ in argon. To prevent evaporation of $\mathrm{Mn}$ during this heat treatment, the surface of the specimens was coated with a mixture of $\mathrm{Si}_{2} \mathrm{O}, \mathrm{Na}_{2} \mathrm{O}$ and $\mathrm{Al}_{2} \mathrm{O}_{3}$. The plate specimens were spark-cut from the as-solution treated sample and subjected to aging treatments in vacuum capsules at various temperatures ranging from $670 \mathrm{~K}$ to $1370 \mathrm{~K}$, followed by quenching into water. Shape memory effect was measured by bending and extension test. For bending test, the specimen with the dimension of $0.6 \times 4 \times 20 \mathrm{~mm}$ was bent at room temperature by about $4 \%$ using a rod as bending guide and then heated to $870 \mathrm{~K}$ for reverse transformation. For extension test, specimens of $0.6 \times 4 \times 15 \mathrm{~mm}$ with the standard grip shoulders were extended by various amounts (up to $8 \%$ ) at room temperature, and the elongation by tensile deformation and its length recovery after heating to $870 \mathrm{~K}$ were measured using a measuring microscope. Recovery force was evaluated with those specimens used for extension SME test. Stress-induced martensite was observed using atomic force microscopy (AFM) from Digital Instrument 3000 at tapping mode in air.

Table 1: Alloy composition of the new alloys and conventional ones (mass\%)

\begin{tabular}{c|cccccccc}
\hline Alloy No. & Mn & Si & Cr & Ni & Nb & C & Fe & NbC \\
\hline 1 & 28 & 6 & 5 & & & & bal. & \\
2 & 28 & 6 & 5 & & 0.47 & 0.06 & bal. & $0.5($ vol.) \\
3 & 28 & 6 & 5 & & 0.93 & 0.12 & bal. & $1.0($ vol.) \\
4 & 28 & 6 & 5 & & 1.40 & 0.18 & bal. & $1.5($ vol.) \\
& & & & & & & & \\
5 & 14 & 6 & 9 & 5 & & & & \\
6 & 14 & 6 & 9 & 5 & 0.47 & 0.06 & bal. & $0.5($ vol.) \\
7 & 14 & 6 & 9 & 5 & 0.93 & 0.12 & bal. & $1.0($ vol.) \\
8 & 14 & 6 & 9 & 5 & 1.40 & 0.18 & bal. & $1.5($ vol.) \\
\hline
\end{tabular}

\section{RESULTS}

\subsection{Shape memory effect}

Fig. 1 shows the dependence of shape recovery on aging temperature for $\mathrm{Fe}-28 \mathrm{Mn}-6 \mathrm{Si}-5 \mathrm{Cr}$ alloys containing $0.5-1.5 \% \mathrm{NbC}$. The shape recovery was measured by bending test, employing the specimen bent by about $4 \%$ strain. The shape recoveries of the as-solution treated samples of these new alloys and 
the $\mathrm{NbC}$ free $\mathrm{Fe}-28 \mathrm{Mn}-6 \mathrm{Si}-5 \mathrm{Cr}$ alloy are also shown for comparison in the figure. The shape recoveries of the $\mathrm{NbC}$ containing alloys are nearly the same (around $50 \%$ ) as that of the $\mathrm{NbC}$ free alloy in the case of the as-solution state. However, for the $\mathrm{NbC}$ containing alloys, the shape recovery is increased by aging treatment; especially, the improvement of the shape recovery is remarkable by aging at higher temperatures. For example, with aging treatment at $1070 \mathrm{~K}$ for $2 \mathrm{~h}$, the shape recoveries of the three $\mathrm{NbC}$ containing alloys are all increased to about $90 \%$ from about $50 \%$. For the alloy with $1.0 \% \mathrm{NbC}$, the aging treatment at lower temperatures such as $770 \mathrm{~K}$ or $870 \mathrm{~K}$ is also effective to improve the shape recovery. Fig. 2 shows the shape recoveries for $\mathrm{Fe}-14 \mathrm{Mn}-6 \mathrm{Si}-9 \mathrm{Cr}-5 \mathrm{Ni}$ containing $0.5-1.5 \mathrm{NbC}$ and its reference alloy $(\mathrm{NbC}$ free). As seen in this figure, the shape recoveries of the three $\mathrm{NbC}$ containing alloys are also much improved by aging treatment, especially at higher temperatures. It should be noted in Figs. 1 and 2 that aging treatment at too high temperature becomes less effective to improve SME; the shape recovery is decreased with further increasing aging temperature over $1170 \mathrm{~K}$.

From the results of the dependence of shape recovery on aging treatment temperature, we have known that the aging treatment around $1070 \mathrm{~K}$ for $2 \mathrm{~h}$ is the best to improve SME for all the alloys containing $\mathrm{NbC}$. Therefore, in order to know the effect of the amount of deformation on SME, we have examined only those samples that were subjected to the aging treatment at $1070 \mathrm{~K}$ for $2 \mathrm{~h}$. To evaluate this effect more accurately, the extension SME test was performed instead of the bending test. The results are shown in Fig. 3. It is emphasized that the shape recoveries of $100-80 \%$ are obtained for $1-4 \%$ strains in $\mathrm{Fe}-28 \mathrm{Mn}-6 \mathrm{Si}-5 \mathrm{Cr}-0.5 \mathrm{NbC}$ and for $1-3 \%$ strains in $\mathrm{Fe}-14 \mathrm{Mn}-6 \mathrm{Si}-9 \mathrm{Cr}-5 \mathrm{Ni}-0.5 \mathrm{NbC}$ without the "training". By comparison at $4 \%$ strain, the shape recovery is increased from $50 \%$ to $80 \%$ by addition of $0.5 \% \mathrm{NbC}$ to the current $\mathrm{Fe}-28 \mathrm{Ni}-6 \mathrm{Si}-5 \mathrm{Cr}$ alloy. As a matter of course, the shape recovery is decreased with increasing amount of deformation strain of the test sample. Besides this general dependence, however, we can see a clear indication in Fig. 3 that the decrease in shape recovery with strain for the new alloys with $28 \mathrm{Mn}$ (alloys No. 2,3) is not so rapid compared with the corresponding conventional $\mathrm{Fe}-28 \mathrm{Mn}-6 \mathrm{Si}-5 \mathrm{Cr}$ containing no $\mathrm{NbC}$. The other prominent features seen in this figure are that the shape recoveries of the new alloys with $28 \mathrm{Mn}$ are much better than those of $14 \mathrm{Mn}$ (alloys No. 6 , 8 ), and those with $0.5 \mathrm{NbC}$ are greater than those with 1.0-1.5 NbC. It is also noted that the shape recoveries at $4 \%$ strain in the case of extension SME test are much smaller for all the alloys if compared with those obtained by bending SME test in Figs. 1 and 2 . This may be partly due to that the $4 \%$ strain by bending, which was estimated by a simple formal equation using the bent radius and the specimen thickness, involves much more complicated deformation and then it cannot be equivalent to the $4 \%$ strain by tensile deformation. Nevertheless, this fact may indicate that the recoverable strain in SME may be strongly dependent on the pattern of deformation, more specifically, the formation pattern of stressinduced martensite plates.

\subsection{Recovery force}

In most of the applications of shape memory alloys, the recovery force is also important. For example, when a shape memory alloy is used for pipe coupling, the fastening force is decided by recovery force, and a larger recovery force increases the proof stress of the connected pipe system. In the present study, we have examined the recovery forces of $\mathrm{NbC}$ free and $\mathrm{NbC}$ containing alloys as a function of recovery strain with the tensile-deformed samples. In our experiments, we firstly measured the curve of the shape recovery strain vs. heating temperature by stepwise heating. From this curve, we know the appropriate heating temperature to obtain a certain amount of the recovery strain. In order to measure the recovery force corresponding to this recovery strain, the deformed sample is firstly heated to a pre-determined temperature to produce the expected recovery strain, and then two ends of the same specimen is fixed on the micro-tensile machine at room temperature. After this, the specimen is heated again all the way to above Af temperature and the maximum stress appeared in this heating process is regarded as a recovery force for an intended shape recovery strain. The recovery force measured in this way is plotted as a function of shape recovery strain in Fig. 4 . Besides the new alloys with $0.5 \mathrm{NbC}$, the recovery forces for the as-solution treated and 5 cycle-"trained" Fe-28Mn-6Si-5Cr are also shown for comparison in this 
figure. The amounts of tensile deformation of the samples before the test were $3.1,4.1,4.1$ and $5.0 \%$ for the as-solution treated, "trained" Fe-28Mn-6Si-5Cr, Fe-28Mn-6Si-5Cr-0.5NbC and Fe-14Mn-6Si-9Cr$5 \mathrm{Ni}-0.5 \mathrm{NbC}$, respectively. The recovery force is remarkably increased for the new alloys with $\mathrm{NbC}$, the amount of the increase being 50-70 $\mathrm{MPa}$ for various shape recovery strains. However, regrettably, the recovery forces of the new alloys do not reach that of the "trained" $\mathrm{Fe}-28 \mathrm{Mn}-6 \mathrm{Si}-5 \mathrm{Cr}$ as seen in this figure.

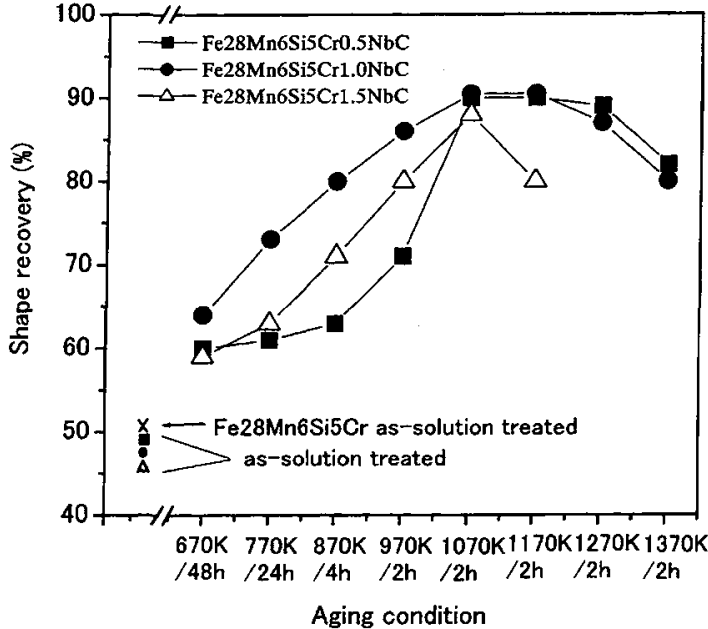

Figure 1: Effect of aging temperature on shape recovery in three kinds of $\mathrm{Fe}-28 \mathrm{Mn}-6 \mathrm{Si}-5 \mathrm{Cr}$ alloys containing $0.5,1.0$ and $1.5 \% \mathrm{NbC}$. Aging time is also indicated for each aging temperature.

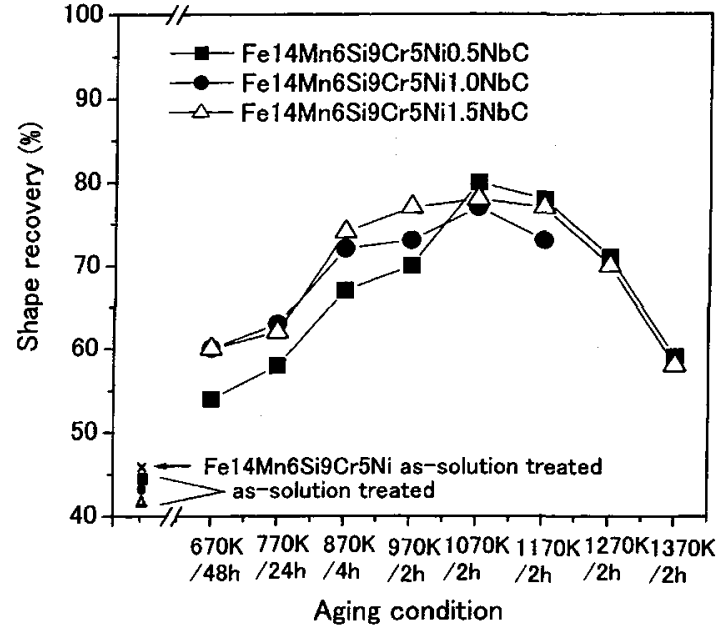

Figure 2: Effect of aging temperature on shape recovery in three kinds of $\mathrm{Fe}-14 \mathrm{Mn}-6 \mathrm{Si}-9 \mathrm{Cr}-5 \mathrm{Cr}$ alloys containing $0.5,1.0$ and $1.5 \% \mathrm{NbC}$. Aging time is also indicated for each aging temperature.

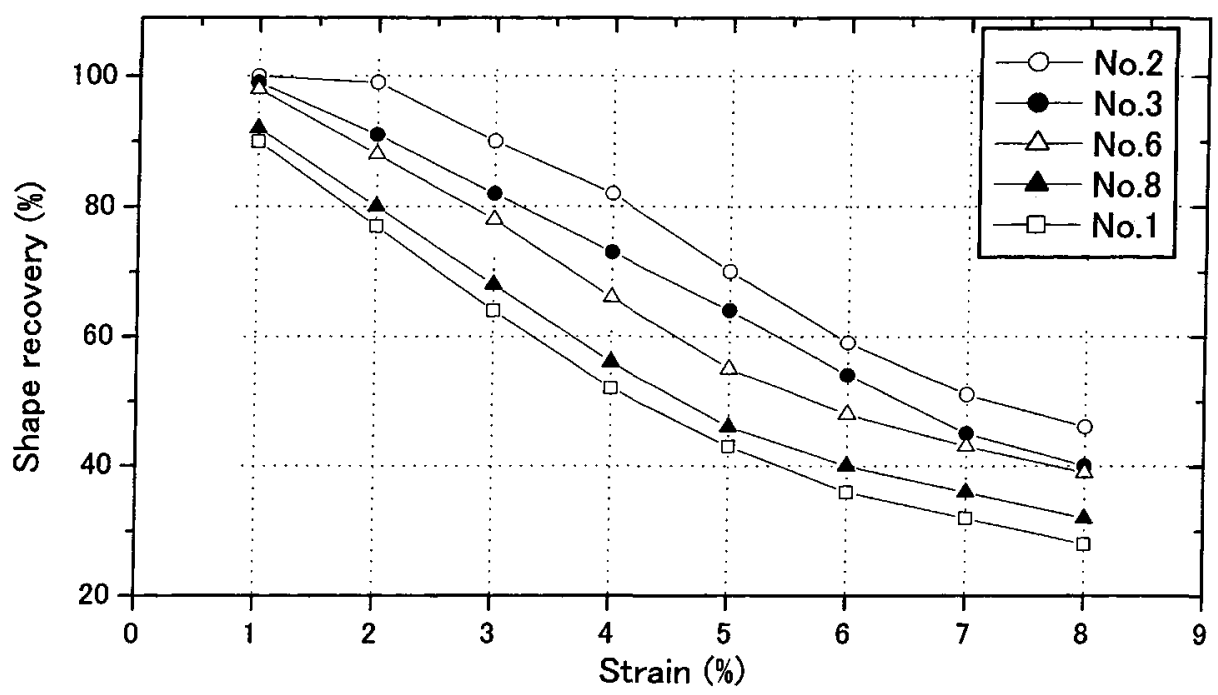

Figure 3: Effect of strain on shape recovery for tensile deformation. Alloys No. 2 and 3 with $28 \%$ Mn show better shape recoveries than those with $14 \% \mathrm{Mn}$ (No. 6 and 8). Alloys with $0.5 \mathrm{NbC}$ exhibit better shape recoveries than those with 1.0 or $1.5 \mathrm{NbC}$. The shape recovery for $\mathrm{Fe}-28 \mathrm{Mn}-6 \mathrm{Si}-5 \mathrm{Cr}$ (No. 1) is also shown for comparison. 


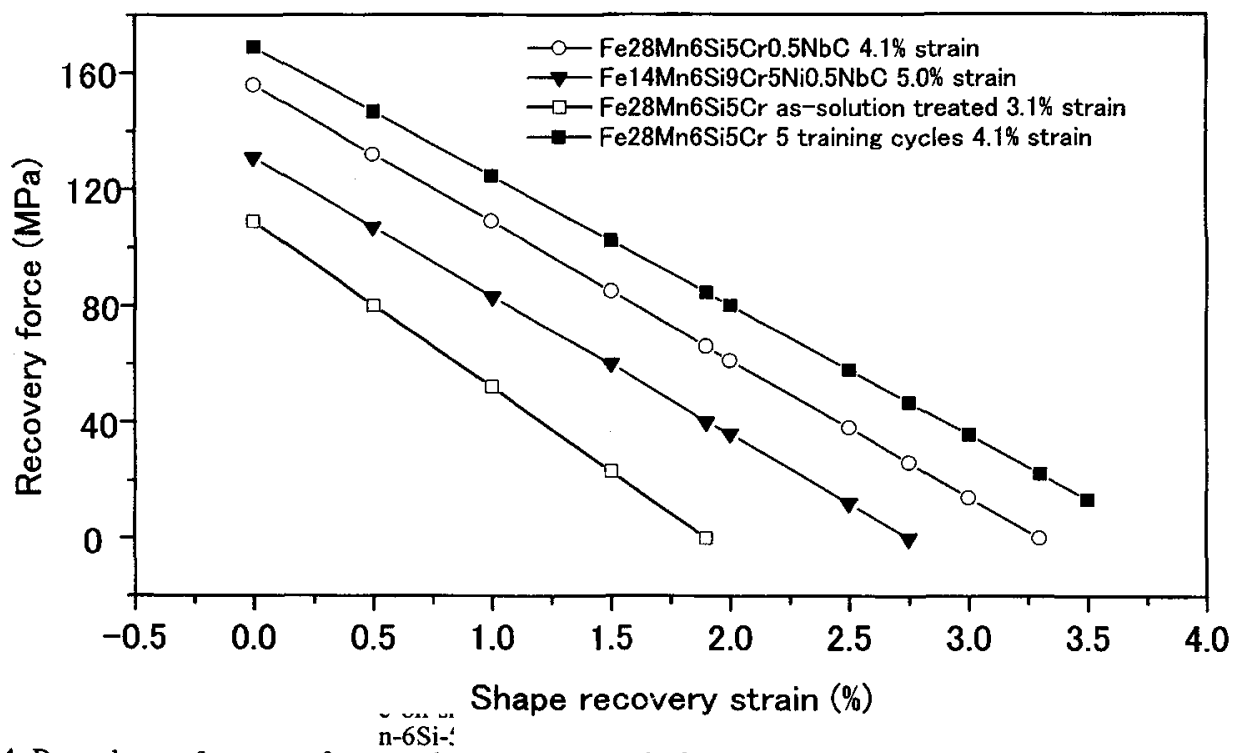

Figure 4: Dependence of recovery force on shape recovery strain for $\mathrm{Fe}-28 \mathrm{Mn}-6 \mathrm{Si}-5 \mathrm{Cr}-0.5 \mathrm{NbC}$ and $\mathrm{Fe}-14 \mathrm{Mn}-6 \mathrm{Si}-9 \mathrm{Cr}-5 \mathrm{Ni}$ $0.5 \mathrm{NbC}$. The recovery force for $\mathrm{Fe}-28 \mathrm{Mn}-6 \mathrm{Si}-5 \mathrm{Cr}$ containing no $\mathrm{NbC}$ is also plotted for the cases of as-solution treated sample and 5-cycled "trained" sample. The specimens were extended by 3-5\% at room temperature before the test to measure the recovery force

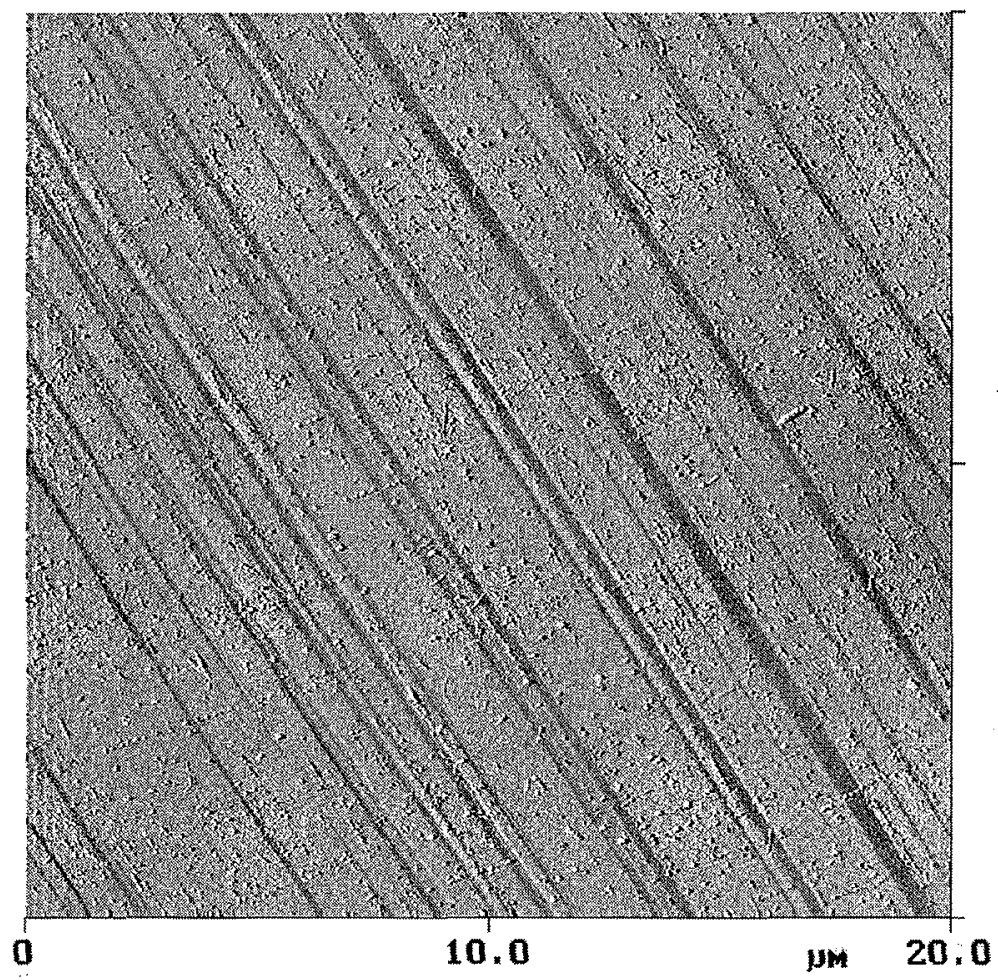

Figure 5: AFM image of stress-induced martensite plates for $\mathrm{Fe}-14 \mathrm{Mn}-6 \mathrm{Si}-9 \mathrm{Cr}-5 \mathrm{Ni}-0.5 \mathrm{NbC}$ aging treated at $1070 \mathrm{~K}$ for $2 \mathrm{~h}$ The sample was tensile deformed by $3.6 \%$ at room temperature. All the martensite plates have the same color in the original color picture, indicating that they have the same variant. Note that thin martensite plates are uniformly distributed. 


\section{DISCUSSION}

As described in the preceding section, addition of small amounts of $\mathrm{Nb}$ and $\mathrm{C}$ to the current $\mathrm{Fe}-\mathrm{Mn}-\mathrm{Si}$ based shape memory alloys is quite effective to improve shape recovery. It was observed in the aged samples by transmission electron microscope (TEM) that there exist very fine NbC precipitates of 10-20 $\mathrm{nm}$ in size accompanying large strain contrast in the austenite. Furthermore, our preliminary experiments with TEM and AFM (atomic force microscope) [9, 10] strongly indicate that the resulting deformation structures in those $\mathrm{NbC}$ containing alloys are exactly what we have expected, that is, it was observed by TEM that very thin stress-induced martensite plates with about $1 \mathrm{~nm}$ are uniformly distributed and most of martensite plates observed by AFM have the same variant. An example of the AFM micrographs is shown in Fig. 5. Thin martensite plates with the same contrast are seen in this micrograph. These martensite plates have the same color in the original AFM color picture, which means that they are the same variant. It is also noted that the martensite plates are uniformly distributed. These characteristics on the stress-induced martensite plates revealed by AFM are exactly the same as our recent AFM observations on the "trained" sample in Fe-Mn-Si based shape memory alloys [6, 7]. These preliminary results convince us that fine $\mathrm{NbC}$ precipitates in austenite can produce almost the same deformation structures as those of the "trained" sample as predicted by Kajiwara [4], which results in very good shape memory effect in $\mathrm{Fe}-\mathrm{Mn}$-Si based shape memory alloys. It is expected that these NbC precipitates will also increase the strength of austenite and, then, effectively prevent slip deformation when external stress is applied for shape change. This would be another factor to improve SME in the NbC containing alloys. It should be noted that the recovery strength of the new alloys is significantly increased as seen in Fig. 4 although it cannot still reach that of the "trained" sample

\section{Acknowledgments}

One of the authors (D. Z. Liu) expresses sincerely thanks to the Science and Technology Agency of Japanese Government for providing the STA fellowship

\section{References}

1. A. Sato, E. Chishima, K. Soma and T. Mori, Acta Met., 30, 1177 (1982).

2. K. Ogawa and S. Kajiwara, Mater. Trans. JIM, 34, 1169 (1993).

3. T. Kikuchi, S. Kajiwara and Y. Tomota, Mater. Trans. JIM, 36, 719 (1995).

4. S. Kajiwara, Mat. Sci. \& Eng. A273-275, 67 (1999).

5. S. Kajiwara and K. Ogawa, Materials Science Forum, 327-328, 211 (2000).

6. D. Z. Liu, T. Kikuchi, S. Kajiwara and N. Shinya, Materials Science Forum, 327-328, 215 (2000).

7. D. Z. Liu, S. Kajiwara, T. Kikuchi, N. Shinya, D. F. Wang and W. X. Liu, Mater. Trans. JIM, 41, 593 (2000).

8. Y. Ono, H. Nakatsu and S. Takaki, J. Japan Inst. Metals (in Japanese), 61, 560 (1997).

9. T. Kikuchi, D. Z. Liu, K. Ogawa, S. Kajiwara and N. Shinya, Proc. JIM Spring Meeting, Yokohama, 2000, p.251.

10. D. Z. Liu, S. Kajiwara, T. Kikuchi and N. Shinya, Proc. JIM Spring Meeting, Yokohama, 2000, p.251. 